\title{
Reproducibility of water drinking test performed at different times of the day
}

\author{
Reprodutibilidade do teste de sobrecarga hídrica realizado em diferentes \\ horários do dia
}

\author{
Flavio Mac Cord Medina ${ }^{1}$ \\ Fabrício Kafury Pereira Rodrigues ${ }^{2}$ \\ Paulo de Tarso Ponte Pierre Filho ${ }^{3}$ \\ Tiemi Matsuo ${ }^{4}$ \\ José Paulo Cabral de Vasconcellos ${ }^{5}$ \\ Vital Paulino Costa ${ }^{6}$
}

This paper was conducted at the Glaucoma Service, State University of Campinas - UNICAMP - Campinas (SP) - Brazil.

${ }^{1} \mathrm{MD}$, Department of Ophthalmology - Universidade Estadual de Campinas - UNICAMP - Campinas (SP) Brazil.

${ }^{2} \mathrm{MD}$, Department of Ophthalmology - UNICAMP - Campinas (SP) - Brazil.

MD, Department of Ophthalmology - Santa Casa de Sobral - Sobral (CE) - Brazil.

${ }^{4}$ Associate Professor - Universidade Estadual de Londrina - UEL - Londrina (PR) - Brazil.

${ }^{5} \mathrm{MD}$, Department of Ophthalmology - UNICAMP - Campinas (SP) - Brazil.

${ }^{6} \mathrm{MD}$, Department of Ophthalmology - UNICAMP - Campinas (SP) - Brazil.

Correspondence address: Flavio Mac Cord Medina. Clínica São Vicente. Rua João Borges, 204 - Rio de Janeiro (RJ) CEP 22451-100

E-mail: fmaccord@ hotmail.com

The authors have no commercial interests in this article.

Recebido para publicação em 27.04.2007

Última versão recebida em 03.03.2009

Aprovação em 16.03.2009

Nota Editorial: Depois de concluída a análise do artigo sob sigilo editorial e com a anuência do Dr. Francisco Eduardo Lopes de Lima sobre a divulgação de seu nome como revisor, agradecemos sua participação neste processo.

\begin{tabular}{l} 
ABSTRACT \\
\hline Purpose: To evaluate the reproducibility of water drinking test (WDT) \\
performed at different times of the day, in primary open angle glaucoma \\
(POAG) patients and normal individuals. Methods: Fifteen patients \\
with POAG and 30 normal individuals underwent three WDTs at dif- \\
ferent times of the day (7 AM, 12 PM, and 5 PM) on 3 different days. \\
Test results in POAG patients and normal individuals were compared. \\
Agreement and correlation of intraocular pressure (IOP) baseline levels, \\
peak levels, and IOP change (peak IOP - baseline IOP) on tests perfor- \\
med at different times were evaluated. Only right eye measurements \\
were analyzed. Results: Mean baseline IOP, peak IOP and IOP change \\
were significantly higher in POAG patients than in normal individuals, \\
at all time intervals (p<0.05). The Bland-Altman analysis demonstrated \\
limits of agreement for IOP peak levels and IOP changes larger than the \\
clinically acceptable (>3 mmHg), even though Pearson's test revealed \\
good correlation among the results. Conclusion: The mean IOP peak \\
and mean IOP change observed during WDT are significantly higher \\
in POAG patients than in control individuals. Low levels of agreement \\
among WDTs performed at different times of the day suggest a poor \\
reproducibility of WDT, which may limit its applicability for the diag- \\
nosis and follow-up of glaucoma.
\end{tabular}

Keywords: Glaucoma; Tonometry, ocular; Reproducibility of results; Intraocular pressure; Diagnostic techniques and procedures

\section{INTRODUCTION}

Intraocular pressure (IOP) is the main risk factor for the development and progression of glaucoma and it varies during the day ${ }^{(1)}$. Glaucoma treatment, whether medicinal or surgical, aims at reducing IOP levels in order to prevent disease progression. IOP fluctuation has been shown to be important for the diagnosis, treatment and prognosis of glaucoma ${ }^{(2-3)}$.

The fact that undetected IOP peaks during routine examinations were related to progression of visual field loss emphasized the value of the diurnal tension curve (DTC) in the management of glaucoma patients ${ }^{(4)}$. However, the DTC is considered troublesome by the physician and uncomfortable for the patient. Therefore, there have been efforts to find alternative methods of detecting IOP spikes.

In the past, water drinking test (WDT) was frequently used to diagnose glaucoma patients ${ }^{(5)}$. The mechanism by which the WDT increases the IOP has not been clarified ${ }^{(2)}$. Initial studies suggested that changes in blood 
osmolarity were responsible for the increase in $\mathrm{IOP}^{(5-6)}$. An increase in blood osmolarity reduces aqueous humor $(\mathrm{AH})$ production and drainage, whereas a reduction in blood osmolarity (as seen during WDT) increases the production and drainage of $\mathrm{AH}^{(7)}$. In 1960, Drance observed that, similarly to normal individuals, glaucomatous patients responded to reduced blood osmolarity with an increase in AH production, but AH drainage did not increase enough to maintain adequate IOP levels in $64 \%$ of eyes with glaucoma ${ }^{(8)}$.

Subsequent studies ${ }^{(9-10)}$ revealed low sensitivities and specificities of WDT for the diagnosis of glaucoma. In one publication, $38.4 \%$ of 13 normal individuals undergoing WDT showed an increase in IOP greater than $8 \mathrm{mmHg}$ and $30.7 \%$ showed peak IOPs higher than $24 \mathrm{mmHg}^{(9)}$. In another study, WDT results were found to be similar among normal, ocular hypertensive, and glaucomatous individuals ${ }^{(10)}$.

For these reasons, WDT has been virtually abandoned until recently, when a series of studies suggested that the WDT could be employed not as a diagnostic test, but rather as a tool to assess IOP peaks and changes ${ }^{(11-13)}$. After performing the WDT, the mean IOP peak and IOP change were found to be significantly higher in a group of patients that exhibited progression of visual field defects than in a group that did not progress ${ }^{(11)}$. Moreover, patients surgically treated for glaucoma demonstrated smaller IOP changes after the WDT, when compared with clinically treated patients ${ }^{(13)}$.

However, there are no studies in the literature evaluating the variability of WDT in relation to time of performance. Hence, the purpose of this study was to investigate the reproducibility of WDT at different times of the day in normal individuals and patients with primary open angle glaucoma (POAG).

\section{METHODS}

The study sample consisted of 15 individuals with POAG consecutively selected from the Glaucoma Sector of the State University of Campinas, and 30 normal individuals recruited from volunteers of the community, institution staff, and spouses or friends of patients. The study was approved by the Ethics Committee of the State University of Campinas and conducted according to the tenets of Declaration of Helsinki and Health National Council resolution $\mathrm{n}^{\circ}$ 196/96.

All individuals underwent an ophthalmologic exam that included best-corrected visual acuity, slit-lamp examination, Goldmann applanation tonometry, gonioscopy using Zeiss lens, optic disc assessment with a 78-diopter lens under dilated pupils, and automated achromatic perimetry (24-2 program, Sita Standard Strategy, Humphrey Field Analyzer 750, Humphrey-Zeiss, Dublin, CA, EUA).

All recruited participants were 18 years or older, had corrected visual acuity better than 20/40 in one eye, and spherical equivalent $\leq \pm 5$ diopters. Individuals with POAG were defined as having: history of IOP more than or equal to $21 \mathrm{mmHg}$ in at least one eye before onset of treatment, gonioscopy revealing an open angle, presence of typical visual field glaucoma defects (determined by one of Anderson's criteria) ${ }^{(14)}$, and optic disc showing a localized defect of the neuroretinal rim, cup-todisc ratio $\geq 0.6$, optic disc hemorrhage, or cup-to-disc ratio asymmetry $>0.2^{(15)}$. Normal individuals have normal optic discs (cup-to-disc ratio $\leq 0.3$ with no localized defects in neuroretinal rim), open angles at gonioscopy, IOP less than $21 \mathrm{mmHg}$ on two different days, and no visual field defects. Exclusion criteria included: pregnancy, previous ocular surgery or laser, retinal diseases, corneal scars, neurological pathologies that could influence visual field, and incapacitating systemic disease (cerebral vascular disease, senile dementia, severe heart failure). Patients presenting advanced glaucoma also were excluded from this study because of the risk of worsening of visual field defects in the period of hypotensive therapy discontinuation.

Required washout periods before the first WDT were 4 weeks for $\beta$-adrenergic antagonists and prostaglandins analogues, 2 weeks for adrenergic agonists, and 5 days for cholinergic agonists and carbonic anhydrase inhibitors. A safety check with IOP measurement was required after 2 weeks for all patients undergoing a 4-week washout. At that time, patients whose IOPs had risen to levels deemed to be detrimental were excluded from the study.

The water drinking test consisted of:

1. A six-hour period of fasting.

2. Initial IOP reading.

3. Intake of one liter of water during a period of not more than five minutes.

4. After drinking water, IOP was measured every 15 minutes for one hour.

Each patient performed the WDT at three occasions at different times of the day (7:00 h, 12:00 $\mathrm{h}$ and 17:00 h). The interval between each WDT was 1 week. The same calibrated Goldmann's tonometer was used for all IOP measurements. The same observer, masked to patient's diagnosis and masked to previous IOP measurements obtained at different WDTs, performed all IOP measurements.

The Student's $t$ test was used to compare continuous variables between groups, the Fisher's exact test was used to compare categorical data, and analysis of variance for repeated measures was used to compare IOP measurements within the same group. A p-value of less than 0.05 was considered statistically significant.

Bland-Altman analysis was applied to assess the agreement between IOP peaks and IOP changes (peak IOP - baseline IOP) obtained at different timings ${ }^{(16)}$. The linear regression analysis was performed to evaluate the correlation between IOP measurements obtained at different times of the day. We considered $\mathrm{r}$ values above 0.8 as indicative of a strong correlation, $\mathrm{r}$ values between 0.5 and 0.8 as a moderate correlation, and $\mathrm{r}$ values below 0.3 as a weak correlation. Only the results of the right eye (RE) were included for analysis in this study. 
Data were analyzed using the GLM procedure of SAS (SAS Inst., Inc., Cary, NC).

\section{RESULTS}

Demographic characteristics of glaucoma patients and normal individuals are shown in Table 1. Both groups had similar demographic characteristics, except for race. White individuals were more frequent in normal individuals (83.3\%) than in glaucoma patients $(53.3 \%)$.

The mean IOPs at baseline (before the WDT) and mean peak IOPs obtained during the WDT were significantly higher in POAG patients than in normal individuals at all time intervals $(p<0.0001)$. The mean IOP changes during the WDT showed a tendency towards a higher level in POAG patients when the test was perfomed at 7:00 $\mathrm{h}$ and 12:00 $\mathrm{h}$ and presented a statistically significant higher level in glaucoma patients than in normal individuals when the WDT was performed at 17:00h. There were no statistically significant difference among mean IOP peaks $(\mathrm{p}=0.962)$ and mean IOP changes $(p=0.690)$ at the different timings in glaucoma patients. Also, there were no statistically significant difference among mean IOP peaks $(\mathrm{p}=0.670)$ and mean IOP changes $(\mathrm{p}=0.964)$ at the different timings in normal individuals (Table 2).

We evaluated the frequency of individuals showing differences in IOP peaks and IOP changes greater than or equal to $3 \mathrm{mmHg}$ between the timings. Differences $\geq 3 \mathrm{mmHg}$ among IOP peak levels at different tests were found in $20 \%$ of glaucoma patients and $23 \%$ of normal individuals. Diffe-

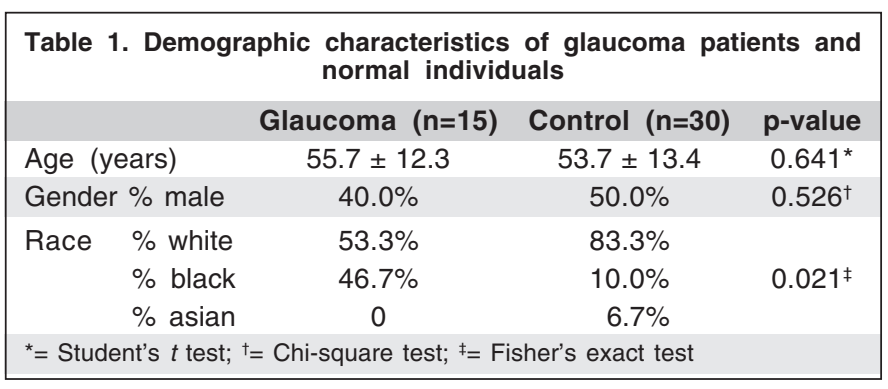

rences $\geq 3 \mathrm{mmHg}$ among IOP changes at different tests were found in $40 \%$ of glaucoma patients and $13 \%$ of normal individuals.

The linear regression analysis applied to IOP peaks at different times in each individual revealed strong correlations for POAG and normal individuals, with $r$ values varying between 0.80 and 0.88 (Figures 1 and 2). The linear regression analysis applied to compare IOP changes at different times in each individual revealed weak to moderate correlations for POAG and normal individuals, with $\mathrm{r}$ values ranging between 0.08 and 0.58 (Figures 3 and 4 ).

Bland-Altman plot demonstrated high vertical dispersion of points and limits of agreement calculated for both IOP peak levels and IOP changes were larger than the clinically acceptable $(>3 \mathrm{mmHg}$ ), for POAG patients and normal individuals (Figures 1 to 4 ).

\section{DISCUSSION}

IOP is the main risk factor for the development and progression of glaucoma. The DTC is currently the most valid diagnostic method to assess the IOP behavior throughout the day. Attempts have been made to develop an alternative, more user-friendly test, capable of providing valuable information regarding IOP peak and fluctuation. A test designed to substitute the DTC in clinical practice should not only duplicate the IOP peak and IOP changes observed at a DTC, but also be reproducible, regardless of the time when it is performed.

The WDT was intended to represent an option for the detection of pressure spikes in glaucomatous patients who apparently have controlled IOPs. It is a test that can be easily performed and repeated several times without major inconveniences $^{(17)}$. Initially, some studies suggested that there was a good correspondence between IOP peaks obtained in the WDT and the maximum DTC values. Helal $\mathrm{Jr}^{(18)}$ verified a similarity between mean maximum IOP levels measured in the DTC and mean IOP peaks obtained with the WDT in 11 glaucoma suspects, indicating that this test could substitute the DTC. However, this study compared mean IOP values, mas-

\begin{tabular}{|c|c|c|c|}
\hline & Glaucoma $(n=15)$ & Control $(n=30)$ & p-value \\
\hline Mean IOP baseline at 7:00 $\mathrm{h}$ & $20.67 \pm 4.24$ & $12.90 \pm 3.63$ & $<0.0001$ \\
\hline Mean IOP baseline at $12: 00 \mathrm{~h}$ & $20.87 \pm 4.24$ & $13.07 \pm 3.18$ & $<0.0001$ \\
\hline Mean IOP baseline at $17: 00 \mathrm{~h}$ & $20.07 \pm 2.76$ & $13.33 \pm 3.15$ & $<0.0001$ \\
\hline Mean peak IOP at 7:00 $\mathrm{h}$ & $25.07 \pm 5.59$ & $16.13 \pm 4.43$ & $<0.0001$ \\
\hline Mean peak IOP at $12: 00 \mathrm{~h}$ & $25.13 \pm 4.12$ & $16.40 \pm 3.84$ & $<0.0001$ \\
\hline Mean peak IOP at $17: 00 \mathrm{~h}$ & $24.93 \pm 4.20$ & $16.57 \pm 3.77$ & $<0.0001$ \\
\hline Mean IOP change at $7: 00 \mathrm{~h}$ & $4.40 \pm 2.67$ & $3.23 \pm 1.77$ & 0.0871 \\
\hline Mean IOP change at $12: 00 \mathrm{~h}$ & $4.27 \pm 2.63$ & $3.33 \pm 1.75$ & 0.1626 \\
\hline Mean IOP change at $17: 00 \mathrm{~h}$ & $4.87 \pm 2.72$ & $3.23 \pm 2.31$ & 0.0413 \\
\hline (Student's $\mathrm{t}$ test) & & & \\
\hline
\end{tabular}




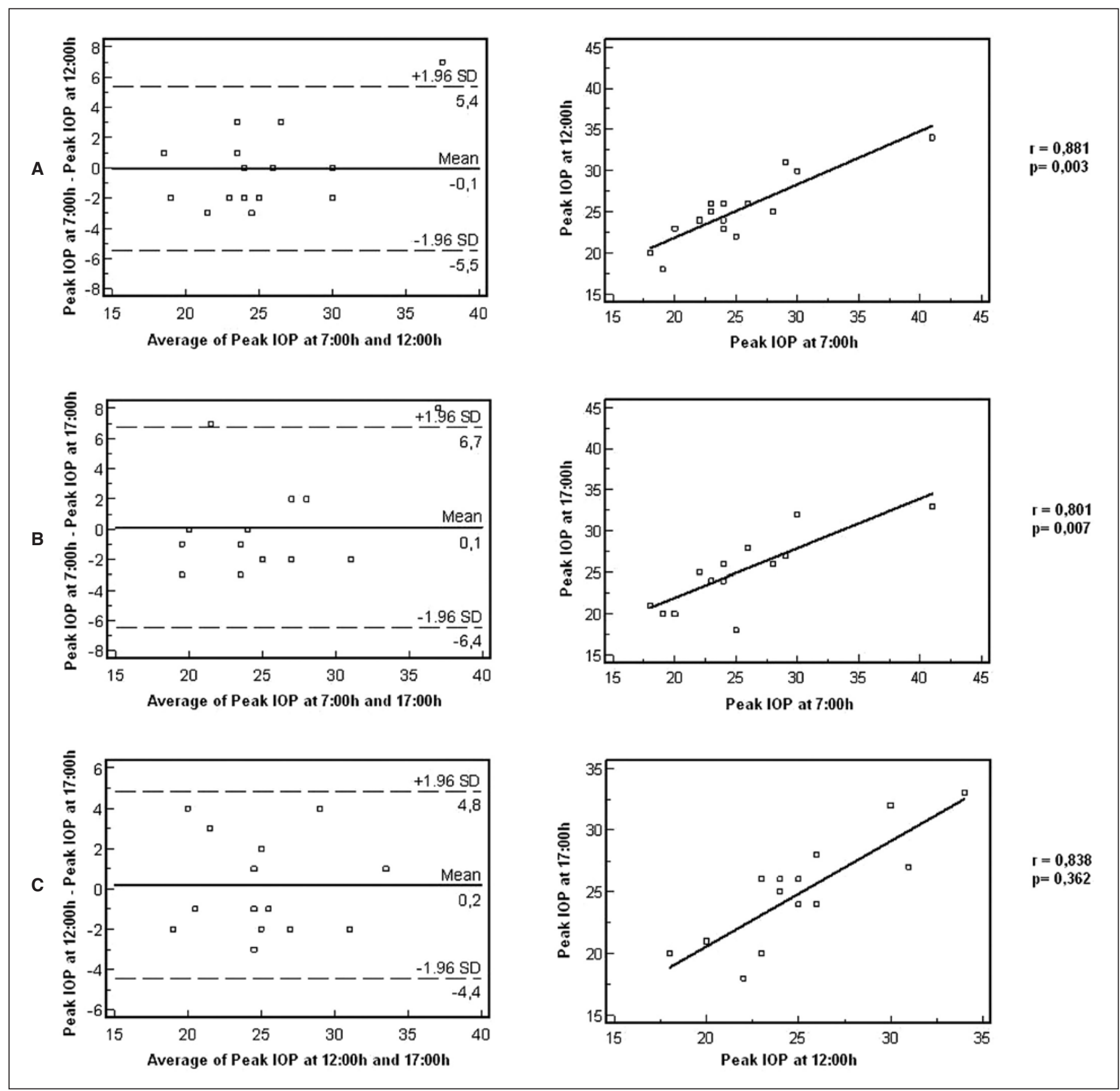

Figure 1 - Bland-Altman and linear regression analysis of IOP peaks during the WDT in glaucoma patients comparing different time intervals (A: 7:00 h vs. 12:00 h; B: 7:00 h vs. 17:00 h; C: 12:00 h vs. 17:00 h)

king the differences in each individual's measurements. In fact, in the present study, we also demonstrated that mean IOP peaks and mean IOP changes were not significantly different when we compared results of WDTs performed at different times of the day.

Miller ${ }^{(19)}$ compared the peak IOPs obtained after the WDT and the maximum IOPs measured in a DTC and concluded that there was significant relationship between them. However, the analysis of the individual results allows us to disclose discrepancies of up to $16 \mathrm{mmHg}$ between the tests.

Bland and Altman suggested that the ideal approach to compare two methods of measurements is to evaluate the agreement between them, rather than comparing means or verifying the existence of correlation between them ${ }^{(16)}$. They proposed the construction of a graphic that plots the differences between the two measurements versus the arithme- 


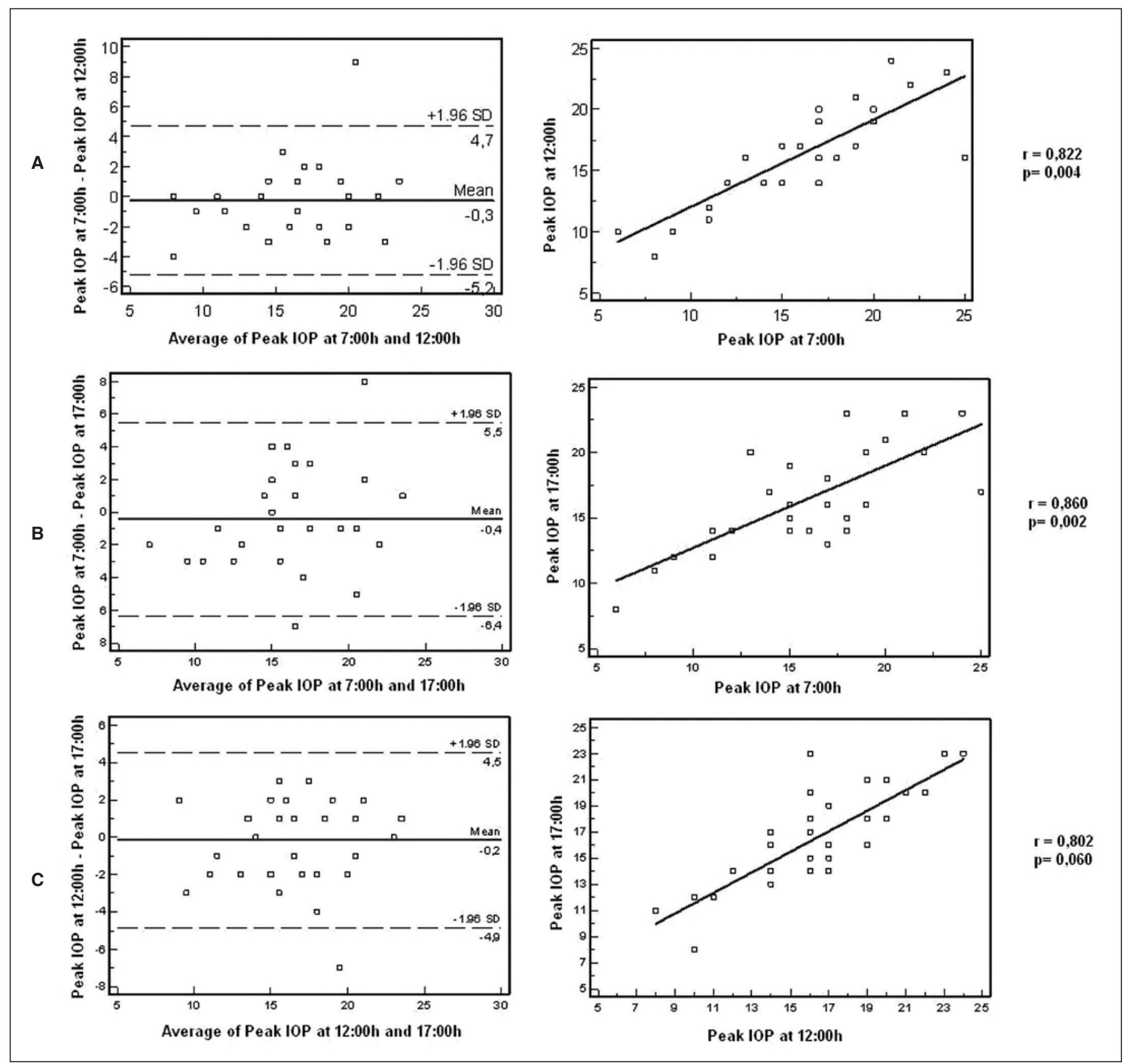

Figure 2 - Bland-Altman and linear regression analysis of IOP peaks during the WDT in normal individuals comparing different time intervals (A: 7:00 h vs. 12:00 h; B: 7:00 h vs. 17:00 h; C: 12:00 h vs. 17:00 h)

tical mean of the two measurements for each tested individual. The purpose of this technique was to assess the discrepancies between the two measurements and calculate limits of agreement, which corresponds to the $95 \%$ confidence interval of the differences between the methods. Methods showing good agreement should display values close to zero and within the limits of the confidence interval. Moreover, limits of agreement should reflect differences that are not clinically important.
In our study, when measurements variability of each individual was assessed, a significant number of individuals were found to present differences greater than or equal to $3 \mathrm{mmHg}$ in both IOP peaks and IOP changes.

There was a strong correlation among IOP peaks obtained at WDTs performed at different times, both in glaucoma patients and normal individuals. However, Bland-Altman analysis demonstrated limits of agreement for IOP peak levels larger than the clinically acceptable $(>3 \mathrm{mmHg})$. 


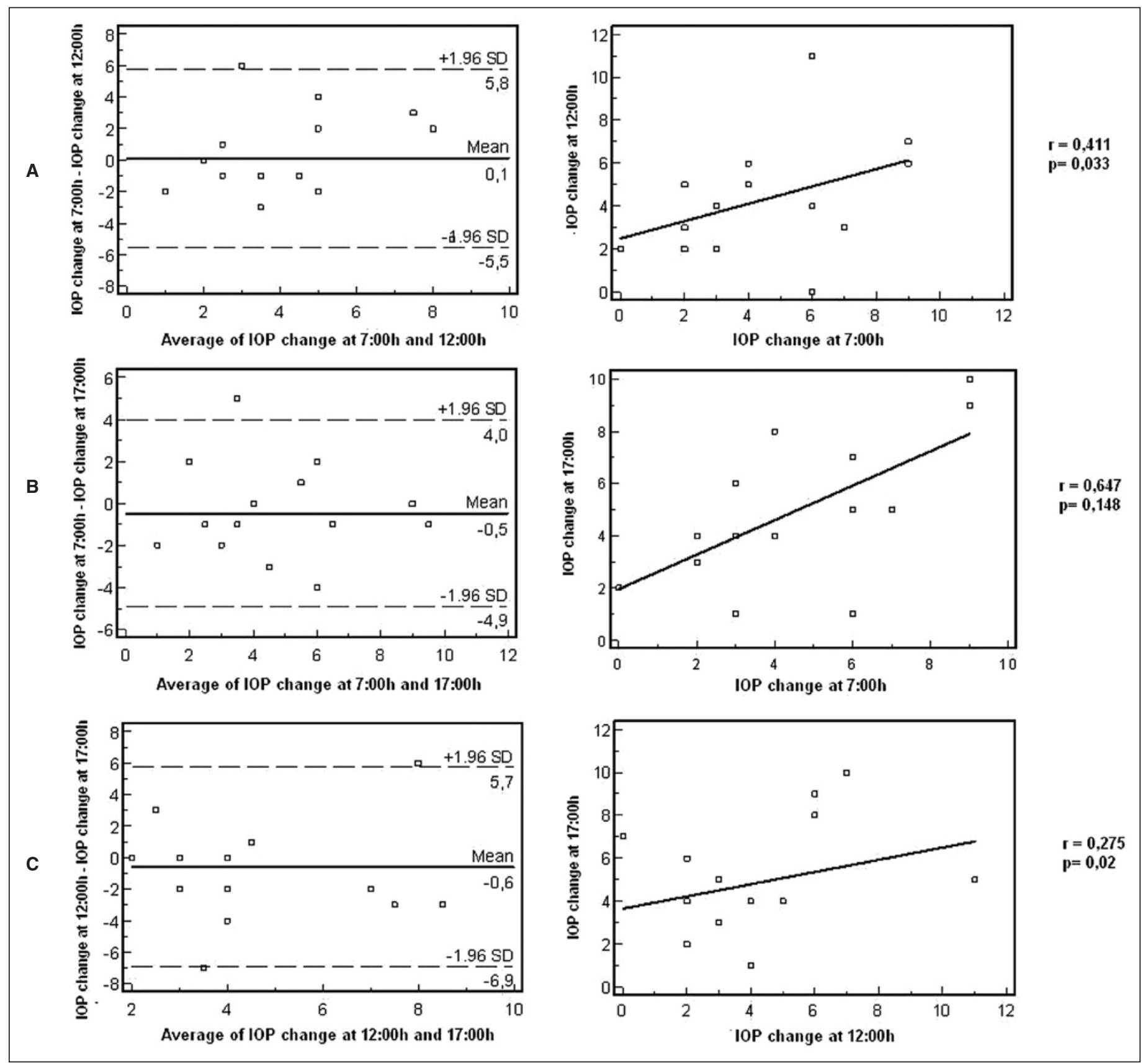

Figure 3 - Bland-Altman and linear regression analysis of IOP changes during the WDT in glaucoma patients comparing different time intervals (A: 7:00 h vs. 12:00 h; B: 7:00 h vs. 17:00 h; C: 12:00 h vs. 17:00 h)

IOP changes in different tests presented low to moderate correlation and limits of agreement also larger than the clinically acceptable ( $>3 \mathrm{mmHg})$, both in glaucoma patients and normal individuals.

Many factors can explain the large variability observed in the WDT. Variables such as previous hydration state, diurnal fluctuation in $\mathrm{AH}$ production and drainage, changes in intestinal water absorption and renal clearance of water overload can justify the discrepancy of the results we obtained.
The limitations of this study were that, as advanced glaucoma patients were excluded, IOP peak levels were lower than expected, what may have raised difficulties to reach statistical significance in results. Difference in race between the groups could have been a limitation of this study, but main comparisons were made inside each group and not between groups.

The results of the present study concur with those of previous studies, demonstrating that the mean IOP peak and mean IOP change obtained with the WDT are significantly higher in glaucomatous patients than in normal individuals. 


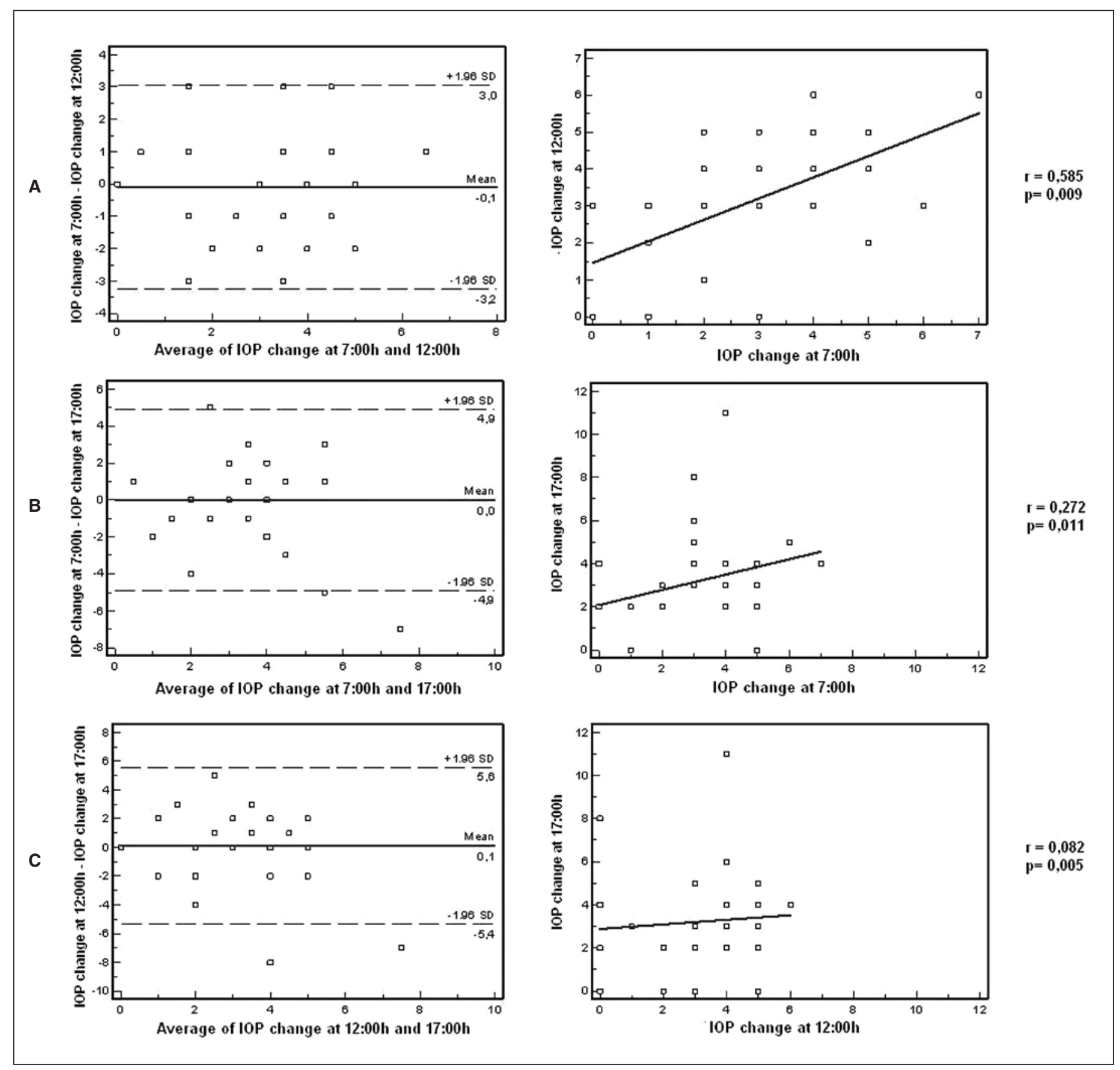

Figure 4 - Bland-Altman and linear regression analysis of IOP changes during the WDT in normal individuals comparing different time intervals (A: 7:00 h vs. $12: 00 \mathrm{~h}$; B: 7:00 h vs. 17:00 h; C: 12:00 h vs. 17:00 h)

However, the agreement between WDT results performed at different times of the day was poor.

The poor reproducibility of the WDT performed at different times of the day represents a limitation to its applicability for the diagnosis and follow up of patients with glaucoma. Further studies are necessary to evaluate the agreement between IOP peaks obtained with the DTC and WDT applying the Bland-Altman analysis. It would also be interesting to apply the Bland-Altman analysis to DTCs performed in dif- ferent days to evaluate the agreement between its results, as this test remains the gold standard to assess the IOP diurnal fluctuation and IOP peak.

\section{ACKNOWLEDGEMENTS}

The author (FMCM) received a grant from Ministry of Education (CAPES) - Brazil. 


\section{RESUMO}

Objetivo: Avaliar a reprodutibilidade do teste de sobrecarga hídrica (TSH) em diferentes horários em que é realizado, em pacientes com glaucoma primário de ângulo aberto (GPAA) e em indivíduos normais. Métodos: Quinze pacientes com GPAA e 30 indivíduos normais foram submetidos a três TSHs, realizados em diferentes horários do dia (às 7:00 h, 12:00 h e 17:00 h), em três dias diferentes. Foram comparados os resultados dos testes em pacientes com GPAA e indivíduos normais. Foram analisadas a concordância e a correlação entre os valores de medida basal, pico e variação de pressão intraocular (PIO) (pico de PIO - PIO basal) nos testes realizados nos diferentes horários. Apenas as medidas do olho direito foram analisadas. Resultados: Os valores médios de medida basal, pico e variação de PIO foram significativamente maiores nos pacientes glaucomatosos que nos indivíduos normais, em todos os horários $(\mathrm{p}<0,05)$. A análise de Bland-Altman apresentou limites de concordância de pico e variação de PIO maiores do que o clinicamente aceitável ( $>3 \mathrm{mmHg}$ ), apesar de o teste de Pearson demonstrar boa correlação entre os resultados. Conclusão: O TSH apresenta valores de pico e variações da PIO significativamente maiores em pacientes glaucomatosos que em indivíduos normais. Os baixos níveis de concordância entre os TSHs realizados em diferentes horários do dia sugerem uma baixa reprodutibilidade do TSH, que pode limitar sua aplicabilidade para diagnóstico e acompanhamento do glaucoma.

Descritores: Glaucoma; Tonometria ocular; Reprodutibilidade dos testes; Pressão intraocular; Técnicas e procedimentos diagnósticos

\section{REFERENCES}

1. Ziemer RC. Circadian variations in intraocular pressure. In: Ritch R, Shields
MB, Krupin T, editors. The glaucomas. $2^{\text {nd }}$ ed. St. Louis: Mosby; 1996. v.1. cap. 21.

2. Susanna Júnior R, Betinjane AJ, Onclinx TM, Biral EL, Barbosa WL. Avaliação da pressão intraocular em olhos glaucomatosos com pressão intraocular normalizada pelo tratamento. Rev Bras Oftalmol. 1995;54(11):837-41.

3. Saccà SC, Rolando M, Marletta A, Macrí A, Cerqueti P, Ciurlo G. Fluctuations of intraocular pressure during the day in open-angle glaucoma, normal-tension glaucoma and normal subjects. Ophthalmologica. 1998;212(2): 115-9.

4. Ziemer RC, Wilensky JT, Gieser DK, Viana MA. Association between intraocular pressure peaks and progression of visual field loss. Ophthalmology. 1991; 98(1):64-9. Comment in: Ophthalmology. 1991;98(9):1323.

5. Leydhecker W. The water-drinking test. Br J Ophthalmol. 1950;34(8):457-79.

6. Winder AF, Siddiqui AA, Donovan HC. Ocular hypertension and systemic responses to water-drinking test. Br J Ophthalmol. 1978;62(6):414-9.

7. De Roetth A Jr. Effect of changes in osmotic pressure of blood on aqueous humor dynamics. AMA Arch Ophthalmol. 1954;52(4):571-82.

8. Drance SM. The significance of the diurnal tension variations in normal and glaucomatous eyes. Arch Ophthalmol. 1960;64:494-501.

9. Susanna Júnior R, Campagna CM. Sobrecarga hídrica: sua importância no diagnóstico do glaucoma. Rev Bras Oftalmol. 1988;47(3):157-8.

10. Roth JA. Inadequate diagnostic value of the water-drinking test. Brit J Ophthalmol. 1974;58(1):55-61.

11. Susanna R Jr, Vessani RM, Sakata L, Zacarias LC, Hatanaka M. The relation between intraocular pressure peak in the water drinking test and visual field progression in glaucoma. Br J Ophthalmol. 2005;89(10):1298-301.

12. Susanna R Jr, Medeiros FA, Vessani RM, Giampani J Jr, Borges AS, Jordão ML. Intraocular pressure fluctuations in response to the water-drinking provocative test in patients using latanoprost versus unoprostone. J Ocul Pharmacol Ther. 2004;20(5):401-10.

13. Medeiros FA, Pinheiro A, Moura FC, Leal BC, Susanna R Jr. Intraocular pressure fluctuations in medical versus surgically treated glaucomatous patients. J Ocul Pharmacol Ther. 2002;18(6):489-98.

14. Anderson DR, Patella VM. Automated static perimetry. $2^{\text {nd }}$ ed. St Louis: Mosby Year Book; 1999.

15. Varma R, Spaeth GL, editors. The optic nerve in glaucoma. Phidelphia: J. B. Lippincott; 1993.

16. Bland JM, Altman DG. Measuring agreement in method comparison studies. Stat Methods Med Res. 1999;8(2):135-60. Review.

17. Carvalho CA, Helal Júnior J. Valor da prova de sobrecarga hídrica no seguimento de pacientes com glaucoma crônico simples em tratamento. Rev Bras Oftalmol. 1988;47(2):81-4.

18. Helal Júnior J. Contribuição ao estudo da pressão intraocular: picos de pressão intraocular na curva diária de pressão e na prova de sobrecarga hídrica. Rev Bras Oftalmol. 1988;47(2):75-80.

19. Miller D. The relationship between diurnal tension variation and the waterdrinking test. Am J Ophthalmol. 1964;58:243-6. 